\section{CASES IN MIDWIFERY.}

By Thous Rajpord, U.D., F.R.C.P.Edin., etc., Consulting Physician to St. Mary's Hospital, Manchester.

[Continued from page 86. .]

Case vi. June 22nd, 1825, at the request of Mrs. Capper, I visited a hospital patient residing at Knot Mill. She was in her ninth month, and was flooding excessively when I saw her. She was faint; her countenance was rery pallid; and her pulse feeble and fluttering. During the previous six weeks she had two attacks, for which there was no obvious cause; but the hæmorrhage was comparatively slight at each of these times. The os uteri was closed and rigid, so that I could not positively ascertain whether the placenta was fixed over it; but I suspected it was. She had no pain. A bandage was now placed round the body, extending well down over the hips, and after placing a firm and large-sized compress orer the uterus, it was very tightly pinned, and in a way to press this organ downwards into the pelvic cavity, and thereby prevent the risk of distension from internal bleeding. I now effectually plugged the ragina with sponge. Through the centre of the first portion of this substance I passed a picce of tape twice, the ends being long enough to hang out externally for the purpose of rendering its withdrawal citsy; it (the sponge) was placed against the os uteri; other sponges were successively passed, until the vagina was completely filled. A napkin, narrowly folded, was now placed over the os externum, which was kept in position by a handkerchief brought between the thighs and tightly pinned before and behind to the circular, or abdominal bandage. A draught, with one drachm of tincture of opium, was given; cool air admitted; some brandy and water was adninistered; and suitable support at proper intervals taken. Great attention was paid to ascertain whether there was any external discharge, but therc was not the slightest appearance; and there was ample proof from the patient:s improvement, that there was no intcrnal hæmorrhage. After remaining some time, I left her.

In the evening, I found her better; no discharge of blood; had some sleep; she had not passed uriue. The catheter introduced, a quantity of water was drawn away. One drachm of tincture of opium was ordered.

The next morning she was very much improved; had slept well; she expressed herself as comfortable in cvery respect, except from the inconvenience of the plug. I now removed the sponges, and along with the last piece some small coagula passed, but there was not the slightest appearance of fresh blood. She continued to go on farourably. At the end of a furtnight, her labour came on, and terminated without any further hæmorrhage. The child was born alive.

REMaRK8. The above case forcibly proves the value of the plug in arresting large discharges of blood. The portion of placenta which was separated, was of considerable size, so that when the membranes ruptured, it fell sideways, and thereby allowed the head of the child to pass, without leading to any further separation. Its organisation was uninjured, or, most likely, the child would not have survived after such profuse discharge. I have min. utely detailed the mode I adopted in plugging the vagina, as I feel convinced this valuable means has fallen into disrepute with some practitioners, entirely from its ineffectual application under their management.

Case vir. April 4th, 1826, I visited a lady residing in Strangeways, who was said to be in great danger from flooding. I found she was at the seventh month of her fourth pregnancy, and that a sudden discharge of blood took place whilst she was engaged in a sedentary occupation. She had fainted before my arrival, and still felt very faint; her countenance was pallid; and her lips rather bleached.
On making an examination, I ascertained, though with some difficulty, from the high position of the os uteri, that it was rigid and undilated. Although I had suspicion, yet I could not feel, that the placenta was located here. Under these circumstances, I wals quite satisficd that nothing promised security to the patient, who had already lost so much blood, but efficetually plugging the viagiua, the application of a broad abdominal bandage, and the large uterine compress; after these measures were completed, a draught, with one drachm of tincture of opium, was given. Some brandy and water, with suitable nutritious articles of diet, as eggs, etc., were administered.

I diligently watehed her for some hours, and was assured that there wis ncither external or internal bleeding. During this period, she continued gradually to improre; her countenance assumed a more natural expression; her lips had a more healthy hue; her pulse improved in tone; and her surface became warm. When I left her, she was enjoined strictly to keep in the recumbent position, and observe positive quietude.

When I called a rain to see her, I found her, upon the whole, better than 1 had anticipated, although she complained of "beating" and pain in the head. She had not slept. She was anxious to have the sponges removed, having a strong desirc to pass urine, although some portion of this fluid nust have dribbled a way. Un the withdrawal of the plug, there was no fresh bleeling. A spirituous lotion to be applied to the head, aud her anodyne repeated. By keeping in bed for some time, and attention to her bowels, etc., she progressively amended.

In a month afterwards, she had again a slight attack of flooding, but which was soon arrested by rest, cold vinegar and water externally applied, cool air, and an acid mixture.

In a fortnight her labour came on, accompanied with flooding, which wis considerable when I reached the bouse. The os uteri was now dilited to about the size of a crownpiece, and felt soft and dilatable. I found a large slip of the placenta crossing over it; and by carrying the finger on to the right side and further within, I perceived the membranes, and through them the head of the child. As the pains were now frequent and strong, and the discharge continued, after placing on a regulating bandage, onc end being fastened to the bed, and the other end held by the nurse, and tirhtened as required, I passed my hand, and first detached a considerable portion of the placenta, and then ruptured the membrares. The bandage was drawn so as equally and firmly to support and compress the uterus as its size lesscned by contraction and the escape of the waters. The pains soon became stronger, and the head of the child shortly engaged itsclf within the os uteri, and the portion of loose placent: took a lateral position, allowing the child to pass by, and which was born alive in about three hours. The placenta, found lying loose in the vagina, was withdrawn. 'There was only the ordinary discharge of blood. The structure of this organ was unbroken.

ReMarks. This case is another cxample of the value of effectively plugging the vagina-no other expedient could have been had recourse to to save blood, and to insure a continuance of pregnancy. Forced delivery, in my judgment, was out of the question; but suppose such an operation had been rashly attenpted, the lives of both the mother and the child would have been most likely sacrificed; and if the membranes had been ruptured under the existing organic state, the child's life would most likely have been lost, and there would have been no certainty of the bleeding being arrested. I detached the placenta as freely as I thought necessary for the passage of the child, as it is better to systematically do this rather than risk the tearing of the structure of this organ by the force it must sustain at each pain when the os uteri has to be dilated by the head of the child after the membranes have been ruptured.

CASE VIII. I was sent for early in the morning, August 5th, 1830, to Mrs. H., residing in Cambridge Street, Chorlton-on-Medlock, who was reported to be in a dangerous 
tate from flooding. She was in the eighth month of her thind pregmancy. She was in bed; and the discharge, which had come on without any known cause, was now excessive. She was very pale and faint. On a vaginal eramination, I found the os uteri closed and firm; the carvix was as near as possible effaced. I suspected the placent was located here, but could not be certain, as it would have been harardous to carry the finger on to search for it. Under these circumstances, I concluded to plug the vagina. $\Delta$ bandage was first put round the body with - large compress over the uterus, placed under it, and tightly fastened. Pieces of sponge were successively introduced until the vagina was completely filled. A retaining bandage, passed between the thighs, was now applied. She had no pains or other signs of labour. One drachm of tincture of opium was administered.

I remained with the patient for some hours, and had her duly supplied with suitable support during this time. I carefully watched her, so as to ascertain whether there was either internal or external bleeding; and felt assured all was right, as the vital powers gradually improved.

When I again visited her in the evening, I found her much improved; there had not been the slightest discharge. As she complained of the plug, and could not pass her urine, I now very cautiously withdrew the sponges, being about fourteen hours from the time they were introduced. The last piece of sponge was coated with coagulated, but there was no fresh, blood. I did not leave the patient (as is $m y$ constant practice under these circumstances) for some time afterwards. One drachm of tincture of opium was ordered.

In the morning, I found her improved; she had slept well, but she was suffering from the effects of loss of blood; pain and throbbing in the head, etc. A spirituous lotion to be applied to the head. Suitable support, with some brandy, was recommended. She was kept in the recumbent position, and these symptoms gradually diminished, and without further interruption went on to the end of her pregnancy.

On September 14th, I was again called to her, being in labour, and again flooding. The pains had commenced about an hour before I was sent for, and the discharge, at first trifling, increased as the pains became stronger. The blood now flowed rapidly. I found the os uteri soft and dilatable, and already dilated to the size of a crownpiece. The placenta was felt through it, and by carrying the finger on the left side (the separated) of it, I touched the membranes, and recognised the head of the child. I had now a bandage placed round the body of the patient, one end of which was firmly fixed to the mattrass, whilst the other end was securely held by the nurse, which was to be gradually tightened, as I directed; the force being applied obliquely downwards. I now introduced my hand, and detached, to a considerable extent, the placenta, and fterwards ruptured the mcmbranes. Whilst the water passed away, the bandage was drawn so as equally and firmly to press on the uterus. The pains increased in power, and soon became expulsatory. On a further examination, I found a large portion of the placenta banging through, and the head of the child just engaging in the os uteri. At this time the hæmorrhage had as nearly as possible ceased. The pains increased in frequency and power, and in about two hours and a half a living child was born. The placenta soon followed, and there was no further flooding. The uterus was felt well contracted. The bandage was adjusted and pinned.

On examining the placenta, the two portions which had left the uterus were readily distinguished : that which caused the first hæmorrhage was firmer, more condensed, less vascular in appearance; that which led to the second attack, as well as that which was artificially detached, was fresher, more rascular, and small clots of blood were seen in its interstitial structure. Its uterine surface was entire and unbroken. She continued to slowly recover; but only required attention to diet, regulation of the bowels, and a strict observance of the recumbent posture.
RExarks. The plug was most effectual in arresting the discharge, and doubtless enabled the patient safely to complete her pregnancy. In detaching the placenta, I carefully avoided lacerating its texture, and separated, as far as I could judge from its connexion with the uterus, so much of it as would allow the child's head to pass without breaking up its structure. This precaution is important for the preservation of the child. (Vide "Remarks on the Sources of Hæmorrhage in Cases of Placenta Prævia, etc."-Lancet, 1847, vol. i, page 219 ; also, 1847, vol. ii, page 302.)

The bandage, which, for the sake of distinction, I described (to my lecture class) as the "regulating bandage", was here of the greatest advantage. By one end of it being held and drawn obliquely downwards as the uterus lessened itself in size, this organ was effectually and uniformly supported, and kept in the axis of the pelvis.

Case IX. I was desired by Mr. F. to visit Mrs. September 20th, 1836, who resided in Hulm. She was at the latter end of the seventh month of her third pregnancy. She had been taken with flooding; but there was nothing to account for the accident; it happened whilst she was sittirg quiet and alone. She had no pain. Mr. F. said cold applications had been freely applied; cool air admitted into the apartment; and he had prescribed an acid mixture, with tincture of opium. He also mentioned that he had plugged the ragina, but notwithstanding all this, the blood continued to flow. From her appearance, she had evidently lost a considerable quantity of blood, for she looked ghastly pale, very faint, and her pulse very frequent and feeble.

On examination, I found a moderate sized piece of sponge lying loosely midway in the ragina, the blood readily escaping past it. I at once withdrew it, and satisfied myself the os uteri was undilated. We agreed to plug the vagina again, and to put on a bandage with a compress under it. Some brandy and water was taken; the yolks of two eggs with brandy were afterwards administered; and crery other means adopted to raise and keep up the depressed vital power. A dose of tincture of opium was given. After effectually plugging the vagina, every precaution was used to show whether there was any external bleeding; but it was completely arrested; and we had full assurance there was no internal hæmorrhage. There being no feeling of increased distension, or sinking tendency; on the contrary, her pulse improved; her skin felt warmer; and there was an improvement in the countenance.

After the lapse of a considerable length of time, I left her, and again visited her in the evening. She was much improved; had no discharge; she complained of throbbing and pain in the head; she had dozed, but had not soundly slept. She had not passed her urine, and complained of an uncomforable feeling from the sponges; but it was deemed right not to withdraw them. A spirituous lotion to be applied to the forehead. To take a draught with forty minims of the tincture of opium. We found her better in the morning; she had slept soundly. There had been no discharge; pulse less frequent and firmer. She complained less of her head; the plug was now withdrawn, and along with it only a little coagulated blood came away. She was now left under the care of her medical attendant, from whom I learnt that she went on satisfactorily to the end of her pregnancy, and that her labour had propitiously ended. The child was alive.

Remarks. This case is especially valuable in showing the difference between the use and the abuse of the plug. The woman doubtless was placed in a safe position, and after the arrest of the bleeding, went safely on to her full time by its right application; whilst, on the other hand, it is not improbable her life might have been lost by the ineffectual plan which had been adopted.

[To be continued.] 